\title{
Implications of cloning
}

SIR - Our recent Letter describing the cloning of sheep by nuclear transfer from an established cell line ${ }^{1}$ has created much popular interest about the biotechnological applications of the technique and the associated animal welfare issues. We wish to clarify these matters.

Five Welsh mountain lambs were born to Scottish blackface foster mothers. Gestation was extended by about 10 days. As reported, two of the lambs died within minutes of birth and a third after ten days. Independent post mortem analysis revealed incomplete urino-genital tract development in all three cases and of the vascular system in two, but in all other regards the animals were normal. The other two lambs are now 8 months old and healthy. The veterinary surgeon elected to deliver one of the lambs by caesarean section. It weighed $6.75 \mathrm{~kg}$ and died soon after birth. The others were born naturally without assistance and weighed 3.2 , $4.15,4.4$, and $4.75 \mathrm{~kg}$. The size of the lambs, with one exception, was within the range for both blackface and Welsh mountain ewes mated to rams of their own breed on the institute farm. The average birth weight for blackface lambs on that farm was $4.1 \mathrm{~kg}$ with a standard deviation of $0.61 \mathrm{~kg}$ and blackface ewes regularly give birth to lambs of over $6 \mathrm{~kg}$ following natural mating. During the past 4 years the largest two lambs weighed $6.6 \mathrm{~kg}$. Welsh mountain lambs born on the same farm weighed between 1.9 and $4.9 \mathrm{~kg}$. While he shared the obvious concern over the death of the lambs, the supervising veterinary surgeon identified no significant health or welfare problems in recipient ewes before or after lambing and although the long gestation periods caused initial concern, reported that they did not lead to significant problems at parturition.

A statistical analysis of the effect on birth weight of the procedures for nuclear transfer was not possible because there were so few observations and it was not clear what comparison should be made. We do not have birth weights of Welsh mountain lambs born to Scottish blackface ewes in our circumstances. However, it was to be expected that lamb birth weight would be greater than that of lambs born to commercial Welsh mountain ewes because the blackface foster mothers were of a larger breed and maternal size is well known to influence birth weight ${ }^{2}$. Furthermore, all the lambs were single lambs, whereas commercial flocks produce a proportion of twins and even triplets, which are smaller at birth. In addition, the ewes were housed to allow careful treatment, rather than being run on the hills. All of these factors would be expected to increase the size of the lambs. Unusually large calves and lambs have been reported by others following a variety of techniques ${ }^{3}$, including embryo culture either alone or in conjunction with pronuclear injection ${ }^{4}$ or nuclear transfer ${ }^{5}$. In the absence of appropriate controls, when it was not possible to know either the extent or the cause of the change, the single large lamb was not highlighted in our paper. The general response to manipulation or culture in these species is the subject of continuing research both in the United Kingdom and elsewhere.

The scientific importance of this work is that development was obtained from a cultured cell line. This technique will almost certainly be used in the first instance or biotechnological applications, such as the production of pharmaceutical proteins in milk, or the provision of organs for transplantation, rather than in commercial agriculture. Biotechnological applications are not dependent upon nuclear transfer for dissemination of transgenic stock, but rather the technique could be used to produce a small number of founder sires which would be used by traditional breeding.

An additional feature of this technique may be a reduction in the numbers of animals used in production of such transgenic founders. At present transgenic livestock can only be produced by injection of DNA into a nucleus in an early embryo ${ }^{6}$. This is inefficient and is associated with random integration, unpredictable expression, mosaicism, and variable germline transmission $^{7}$. Typically several transgenic lines are generated for each application in order to be confident of having at least one with a high level of expression. By contrast, if it is possible to establish procedures for gene targeting in the cultured cells, then genes could be introduced specifically into active sites within the genome before nuclear transfer from cells of the desired genotype.

Although it may become possible to clone from adult cells, to datet the technique has only been shown to work with a single embryo-derived cell type. Concern has also been raised at the possibility of cloning in humans. We do not envisage any situation in which, even if strictly possible, the application of similar techniques in humans would be either clinically useful or ethically acceptable. Such applications would also be illegal under existing UK legislation.

\section{K. H. S. Campbell, J. McWhir}

W. A. Ritchie, I. Wilmut

Roslin Institute, Roslin,

Midlothian EH25 9PS, UK

1. Campbell, K. H. S., McWhir, J., Ritchie, W.A. \& Wilmut, I. Nature 380, 64-66 (1996).

2. Walton, A. \& Hammond, J. Proc. R. Soc. B 125 311-335 (1938).

3. Walker, S. K., Hartwich, K. M., \& Seamark, R. F. Theriogenology 45, 111-120 (1992).

4. Walker, S. K., Heard, T. M. \& Seamark, R. F. Theriogenology 37, 111-126 (1996).

5. Wilson, J. M., et al Anim. Reprod. Sci 38, 73-83 (1995).

6. Pursel, V.G., et al Science 244, 1281-1288 (1989).

7. Carver, A.S., et al Biotechnology 11, 1263-1270 (1993).

\section{Imagine that}

SIR - In his review of Nicholas Humphrey's Soul-Searching - Human Nature and Supernatural Belief, Tim Crane writes that it is a mistake to state that parapsychological phenomena cannot happen; it is enough to say they do not happen. "The fact that we can imagine extrasensory perception and the like is evidence for the fact that they are possible in some sense," he affirms (Nature 379, 685 ; 1996).

Our imagination is evidence for nothing, except for the functioning, or dysfunctioning, of our brain. I am not sure in what "sense" impossible events or phenomena become possible. Throughout history men have imagined - and given very careful, meticulous and exact descriptions of - unicorns, dragons, giants, mermaids, gods, devils, angels, people whose heads grew out of their chests, heavens that revolve around the Earth and much else, to little or no purpose, so far as reality goes.

The fact that things do not happen may mean they are statistically very improbable but are not absolutely impossible, and our 'imagination' has nothing to do with it one way or the other. What has to do with it is physical law. It is absolutely impossible and not merely very unlikely that a heavier mass will orbit a lighter one. The 'fact' that we can imagine the Sun going round the Earth does not change matters and does not constitute evidence for such a thing.

If parapsychological phenomena are eventually proved to be real 'in some sense', that sense will be external physical law, and not because philosophers and other illogical persons have been imagining them.

\section{Ralph Estling}

The Old Parsonage,

Dowlish Wake, IIminster,

Somerset TA19 ONY, UK

\section{Willing genes}

SIR - Daedalus suggests that narcotics users should receive the appropriate genes from the opium poppy or the coca bush which would allow them to synthesize their narcotics endogenously (Nature 380, 206; 1996). There is a simpler way: we already possess the genes for making enkephalin, which has a similar effect. All that Daedalus has to invent is a way of turning them on at will.

M. F. Perutz

MRC Laboratory of Molecular Biology,

Hills Road,

Cambridge CB2 2QH, UK

\section{Correspondence}

Letters submitted for Correspondence should be typed, double-spaced, on one side of the paper only, or e-mailed to nature@nature.com 